\title{
A REMARK ON WEIGHTED INTEGRABILITY
}

\author{
Yi ZHAO AND SONGPING ZHOU
}

Abstract. In this paper, we will generalize the result in weighted integrability to include all positive non-integers $\gamma$ connecting with derivatives of the sum-functions.

Mathematics subject classification (2010): 42A25, 42A50.

Keywords and phrases: Weighted integrability, mean value bounded variation, positivity, monotonicity.

\section{REFERENCES}

[1] JR. R. P. BoAs, Integrability of trigonometric series, J. Math. Oxford Ser. 3 (1952), 217-221.

[2] L. FENG, V. TOTIK AND S. P. ZHOU, Trigonometric series with a generalized monotonicity condition, Acta Math. Sinica English Ser. 30 (2014), 1289-1296.

[3] L. Feng And S. P. Zhou, Trigonometric inequalities in the MVBV condition, Math. Ineq. Appl. 18 (2015), 485-491.

[4] P. HEYWOOD, On the integrability of functions defined by trigonometric series, Quart. J. Math. Oxford Ser. 5 (1954), 71-76.

[5] P. KóRUS, On the uniform convergence of special sine integrals, Acta Math. Hungar., 133 (2011), $82-91$.

[6] M. Z. Wang And S. P. Zhou, Applications of $M V B V$ condition in $L^{1}$ integrability, Acta Math. Hungar. 129 (2010), 70-80.

[7] S. P. Zhou, Monotonicity Condition of Trigonometric Series: Development and Application, Science Press, Beijing, 2012, in Chinese.

[8] S. P. ZHOU, Mean value bounded variation concept in real sense: an application with new techniques to weighted integrability, Math. Ineq. Appl. 19, 1 (2016), 909-922.

[9] S. P. ZHOU, P. ZHOU AND D. S. YU, Ultimate generalization to monotonicity for uniform convergence of trigonometric series, Science China Math., 53 (2010), 1853-1862. /available: arXiv: math.CA/0611805 27 (2006).

[10] A. Zygmund, Trigonometric Series, Cambridge University Press, Cambridge, 1959. 